\title{
The Evolution of Nonhuman Primate Vocalizations: Effects of Phylogeny, Body Weight, and Social Context
}

\section{Citation}

Hauser, Marc David. 1993. The evolution of nonhuman primate vocalizations: Effects of phylogeny, body weight, and social context. American Naturalist 142(3): 528-542.

\section{Published Version}

doi:10.1086/285553

\section{Permanent link}

http://nrs.harvard.edu/urn-3:HUL.InstRepos:3512193

\section{Terms of Use}

This article was downloaded from Harvard University's DASH repository, and is made available under the terms and conditions applicable to Other Posted Material, as set forth at http:// nrs.harvard.edu/urn-3:HUL.InstRepos:dash.current.terms-of-use\#LAA

\section{Share Your Story}

The Harvard community has made this article openly available. Please share how this access benefits you. Submit a story.

Accessibility 


\title{
THE EVOLUTION OF NONHUMAN PRIMATE VOCALIZATIONS: EFFECTS OF PHYLOGENY, BODY WEIGHT, AND SOCIAL CONTEXT
}

\author{
Marc D. Hauser* \\ Animal Communication Laboratory, Department of Zoology, University of California, \\ Davis, California 95616-8761
}

Submitted November 26, 1991; Revised June 8, 1992; Accepted August 7, 1992

\begin{abstract}
E. S. Morton proposed that, in birds and mammals, individuals tend to produce low-frequency atonal vocalizations in highly aggressive situations, whereas they typically produce high-frequency tonal vocalizations during nonaggressive or fearful situations. This hypothesis, referred to as the "motivation-structural (MS) rules," is based on two assumptions: the frequency of a vocalization is negatively correlated with body weight, and large animals are dominant over smaller animals, and thus aggressive vocalizations tend to have a lower pitch than fearful vocalizations. The relationship between body weight and frequency is examined using data on 36 nonhuman primate species representing 23 genera and 474 vocalizations. Results show that there is a statistically significant negative correlation between body weight and frequency: larger species produce relatively lower-pitched vocalizations than smaller species. A test of Morton's MS rules provided overall support for the predicted relationship between motivational state and frequency (i.e., high-frequency calls were produced by fearful individuals, and low-frequency calls were produced by aggressive individuals) but no support for the expected relationship between motivational state and tonality. However, the motivational statefrequency pairing was confounded by the fact that some taxonomic groups (Platyrrhini and Catarrhini) showed a much stronger level of association than other groups (Prosimii and Hominoidea). In summary, therefore, the nonhuman primate data provide only partial support for MS rules. At least three factors may have influenced the outcome of the current test. First, in some species, motivational state may be more closely associated with other acoustic parameters than absolute frequency and tonality. Second, the acoustic structure of nonhuman primate vocalizations is, at least in some cases, more closely associated with an external referent than with the caller's internal state. And third, features of the species-typical habitat have had direct selective effects on signal structure, optimizing for effective propagation through the environment.
\end{abstract}

Based on the intuitions of Darwin (1871), Morton (1977) predicted that, for birds and mammals, the frequency of an individual's voice will often be negatively correlated with its size. Consequently, because larger animals tend to dominate smaller animals, aggressive signals are expected to be relatively low in frequency. Low-frequency signals will also tend to be harsh in quality or noisy owing to the added energy bands that result from a loosely vibrating membrane around the glottis. In contrast, fearful or nonaggressive individuals are expected to produce more tonal and high-frequency vocalizations. These predictions, referred to as

\footnotetext{
* Present address: Departments of Biological Anthropology and Psychology, Harvard University, Cambridge, Massachusetts 02138.
} 
"motivation-structural rules" (hereafter abbreviated as MS rules) have not been evaluated with a large comparative data base, although there are qualitative and quantitative tests using a small sample of calls from a limited set of species (Gouzoules et al. 1984; Seyfarth and Cheney 1984, 1990; August and Anderson 1987; Cheney and Seyfarth 1988; Gouzcules and Gouzoules 1989).

To evaluate MS rules it is first necessary to test the assumption that body weight is negatively correlated with the fundamental frequency of an individual's voice or what listeners perceive as the pitch of the vocal signal. Although this relationship has been examined in a few species (e.g., pigtail macaques [Macaca nemestrina]: Gouzoules and Gouzoules 1990; red deer [Cervus elaphus]: McCoomb 1991), the anurans represent the only taxonomic group in which such analyses have been carried out for a number of species (for a review, see Ryan 1988). In general, results indicate that males attend to call frequency to make decisions during intrasexual aggressive interactions, and females are attracted preferentially to lower-frequency calls. Since large frogs tend to dominate small frogs during competitive interactions, females can use the relationship between body size and call frequency to mate with high-quality males.

Nonhuman primates represent an interesting test group for evaluating the predictions from Morton's $(1977,1982)$ MS rules because there is substantial variation in body weight (pygmy marmosets [Cebuella pygmaea] weigh $0.14 \mathrm{~kg}$, and gorillas [Gorilla gorilla] weigh $128.00 \mathrm{~kg}$; Harvey et al. 1987), and much of the observed acoustic variation is thought to be the result of changes in motivational state during call production (see, e.g., Jürgens 1979). The aims of this article are, first, to evaluate the relationship between body weight and the fundamental frequency of nonhuman primate vocal signals and, second, to examine whether changes in motivational state are associated with changes in the frequency and tonality of the call produced. Such analyses represent a critical step in assessing the evolution of nonhuman primate vocal communication.

\section{METHODS}

\section{Body Weight and Fundamental Frequency}

To extract information on the fundamental ( $\mathrm{Fo}$ ) or base frequency of a call, analyses were restricted to studies providing either high-quality spectrograms or tables of values derived from quantitative measures. Concerning the latter, measures of Fo or the base frequency were either derived by placing an acetate overlay on top of an audiospectrogram or by attaining a digital read-out from the time-amplitude waveform, power spectrum, or spectrogram. When spectrograms were used, values of Fo or the base frequency were obtained by extrapolation from the frequency markers on the spectrogram. I have assumed that the published spectrograms are representative of other exemplars produced by other individuals of the species; if more than one spectrogram was available for a particular call type, I calculated an average value from all exemplars. For torial calls (either pure tones or harmonically structured) exhibiting marked frequency modulation (e.g., chevron-shaped calls), the average frequency of the lowest energy band was calculated by taking the mean of the maximum and minimum 
frequencies. For noisy or atonal vocalizations, the lowest dominant frequency was used.

Two further restrictions were imposed on the data: only vocalizations produced by adults were evaluated, and only species with five or more call types were analyzed; in cases in which data from different subspecies have been published, I used the subspecies with the largest number of call types. The final data set consisted of 36 species from 23 genera and a total of 474 vocalizations (table 1).

Data on body weight (table 1) were extracted from Harvey et al.'s (1987) lifehistory analysis. Although a number of nonhuman primate species exhibit sexual dimorphism with regard to body weight, average body weight values were used for the analyses presented below. The rationale for using average body weight is that current data on the structure of nonhuman primate vocalizations are insufficient to reveal differences between males and females.

\section{Motivational State, Frequency, and Tonality}

A test of MS rules is conducted with data on three call parameters: the motivational state of the caller (inferred from the social context in which the call was produced), frequency, and tonality. Although Morton never operationally formalized the parameters considered, the following set of rules was adopted for classifying vocalizations (table 1). First, motivational state was restricted to the context of aggression. Thus, only calls described by an author as being produced by aggressive or fearful individuals were considered. This restriction was imposed because states of aggression or fear can be identified on the basis of relatively unambiguous behavioral criteria. In most nonhuman primates, aggression and fear are typically accompanied by distinct, species-specific facial expressions (Andrew 1963), and many of the authors cited in this article have used such expressions to guide their assessments of motivational state. Second, frequency (either Fo or the base frequency) was dichotomized into low versus high using each species' frequency range (table 1) as the cutoff point for classification. Because nonhuman primates have the ability to filter different spectral properties of the emitted call (Hauser 1992; Hauser et al. 1993), one might argue that the dominant frequency (i.e., the energy band with the highest relative amplitude), rather than Fo, is the appropriate feature to measure for a test of MS rules. However, most of the published data on nonhuman primate vocal repertoires indicate that, from the perspective of both production and perception, Fo is typically the most salient acoustic feature (see, e.g., Moody et al. 1990). Third, tonality was dichotomized into tonal, which included pure tones and harmonically structured calls, and atonal, which included noisy calls. All calls with mixed structural components (e.g., a pure tone with a noisy overlay or a call that begins with a noisy component then becomes tonal) were excluded.

\section{RESULTS}

\section{Effects of Body Weight on the Fundamental Frequency of a Call}

For nonhuman primates, species within a genus tend to be similar in body weight (Harvey et al. 1987) and often exhibit comparable call types within their 
TABLE 1

Data Set for Analyses of the Relationship between Body Weight, Frequency, and Motivational State

\begin{tabular}{|c|c|c|c|c|c|c|}
\hline \multirow[b]{2}{*}{ Species } & \multicolumn{3}{|c|}{ Number of Calls } & \multirow{2}{*}{$\begin{array}{c}\text { FrEQUENCY } \\
\text { RANGE } \\
(\mathrm{Hz})\end{array}$} & \multirow{2}{*}{$\begin{array}{l}\text { WEIGHT* } \\
\text { (kg) }\end{array}$} & \multirow[b]{2}{*}{ SOURCE $\dagger$} \\
\hline & Total & Aggressive & Fearful & & & \\
\hline \multicolumn{7}{|l|}{ Prosimii: } \\
\hline Galago s. senegalensis $\ddagger$ & 14 & 1 & 1 & $280-5,440$ & .22 & 1 \\
\hline Lemur catta $\ddagger$ & 22 & 3 & 2 & $240-2,530$ & 2.67 & $2,3,4,5$ \\
\hline Nycticebus coucang $\ddagger$ & 7 & 2 & 1 & $130-5,950$ & .92 & 6 \\
\hline Varecia variegata & 5 & 1 & 2 & $200-850$ & 3.60 & 5 \\
\hline \multicolumn{7}{|l|}{ Platyrrhini: } \\
\hline Aotus trivirgatus & 6 & 1 & 1 & $190-1,950$ & 1.22 & 7 \\
\hline Ateles belzebuth & 6 & 2 & 0 & $400-2,850$ & 6.00 & 8 \\
\hline Ateles fusciceps & 9 & 2 & 0 & $200-3,800$ & 9.00 & 8 \\
\hline Callicebus moloch & 11 & 3 & 1 & $200-5,300$ & 1.07 & 9,10 \\
\hline Callithrix jacchus & 9 & 4 & 1 & $500-14,800$ & .31 & 11,12 \\
\hline Cebuella pygmaea $\ddagger$ & 15 & 5 & 2 & $800-14,000$ & .14 & 13 \\
\hline Cebus nigrivittatus & 5 & 0 & 0 & $500-2,400$ & 3.50 & 14 \\
\hline Cebus olivaceus & 12 & 0 & 3 & $800-6,500$ & 3.50 & 15 \\
\hline Saguinus fuscicollis & 13 & 4 & 1 & $3,000-8,250$ & .46 & 16 \\
\hline Saguinus oedipus oedipus $\ddagger$ & 25 & 1 & 0 & $1,150-10,400$ & .49 & 17 \\
\hline Saimiri sciureus $\ddagger$ & 20 & 6 & 1 & $500-11,250$ & .66 & 18 \\
\hline \multicolumn{7}{|l|}{ Catarrhini: } \\
\hline Cercocebus albigena & 5 & 1 & 1 & $200-1,225$ & 7.69 & 19 \\
\hline Cercopithecus aethiops $\ddagger$ & 21 & 6 & 3 & $191-5,600$ & 4.36 & $\begin{array}{c}20,21,22, \\
23,24\end{array}$ \\
\hline Cercopithecus cephus $\ddagger$ & 8 & 1 & 1 & $200-3,509$ & 3.44 & 25 \\
\hline Cercopithecus talapoin $\ddagger$ & 9 & 1 & 0 & $150-20,000$ & 1.25 & 26 \\
\hline Colobus badius tephrosceles $\ddagger$ & 12 & 5 & 2 & $750-4,600$ & 8.24 & 27 \\
\hline Macaca arctoides $\ddagger$ & 13 & 0 & 6 & $250-7,400$ & 7.54 & 28 \\
\hline Macaca fascicularis $\ddagger$ & 15 & 1 & 2 & $400-4,900$ & 4.03 & 29 \\
\hline Macaca fuscata & 40 & 3 & 10 & $170-4,900$ & 10.40 & 30 \\
\hline Macaca mulatta $\ddagger$ & 16 & 3 & 6 & $200-4,320$ & 6.47 & $31,32,33$ \\
\hline Macaca nemestrina $\ddagger$ & 15 & 4 & 7 & $200-3,410$ & 8.28 & 34,35 \\
\hline Macaca radiata $\ddagger$ & 19 & 5 & 4 & $150-10,360$ & 5.41 & 36 \\
\hline Macaca silenus $\ddagger$ & 11 & 1 & 3 & $150-475$ & 5.90 & 37 \\
\hline Mandrillus sphinx & 5 & 1 & 1 & $200-3,000$ & 19.20 & 38 \\
\hline Presbytis entellus $\ddagger$ & 16 & 1 & 1 & $150-4,740$ & 17.15 & 39 \\
\hline Presbytis johnii $\ddagger$ & 16 & 1 & 0 & $150-5,120$ & 11.50 & 39 \\
\hline Theropithecus gelada $\ddagger$ & 22 & 4 & 5 & $215-2,470$ & 17.05 & 40 \\
\hline \multicolumn{7}{|l|}{ Hominoidea: } \\
\hline Gorilla g. berengei $\ddagger$ & 12 & 2 & 3 & $60-518$ & 128.00 & 41 \\
\hline Hylobates agilis & 6 & 2 & 1 & $400-2,400$ & 5.62 & 42 \\
\hline Pan paniscus & 14 & 2 & 1 & $200-2,900$ & 39.10 & 43 \\
\hline Pan troglodytes & 15 & 4 & 2 & $200-2,225$ & 38.10 & 42 \\
\hline Pongo pygmaeus & 5 & 1 & 0 & $200-500$ & 59.00 & 44 \\
\hline
\end{tabular}

* Weights are derived from Harvey et al. (1987).

$\dagger$ Sources for data on call frequency and motivational state: 1, Zimmerman (1985a); 2, Macedonia (1986); 3, Macedonia (1990); 4, Macedonia (1991); 5, Macedonia (in press); 6, Zimmerman (1985b); 7, Moynihan (1964); 8, Eisenberg (1976); 9, Moynihan (1966); 10, Robinson (1979); 11, Epple (1968); 12, M. Norcross and J. Newman (unpublished data); 13, Pola and Snowdon (1975); 14, Robinson (1982); 15, Robinson (1984); 16, Moody and Menzel (1976); 17, Cleveland and Snowdon (1982); 18, Newman (1985); 19, Chalmers (1968); 20, Struhsaker (1967); 21, Cheney and Seyfarth (1988); 22, Seyfarth et al. (1980); 23, Owren and Bernacki (1988); 24, Hauser (1989); 25, Gautier (1978); 26, Gautier (1974); 27, Struhsaker (1970); 28, Bertrand (1969); 29, Palombit (1992); 30, Green (1975); 31, Gouzoules et al. (1984); 32, Hauser (1991, 1992, unpublished data); 33, (Hauser and Fowler 1991; Hauser and Marler, in press $a$, in press $b$ ); 34, Grimm (1976); 35, Gouzoules and Gouzoules (1989); 36, Hohmann (1989a); 37, Hohmann and Herzog (1985); 38, Kudo (1987); 39, Hohmann (1989b); 40, Aich et al. (1990); 41, M. D. Hauser, A. Harcourt, and K. Stewart (unpublished data); 42, Marler and Tenaza (1977); 43, deWaal (1988); 44, Mackinnon (1974).

‡ Species for which fundamental frequency values were derived from quantitative measures are provided by the author(s). 


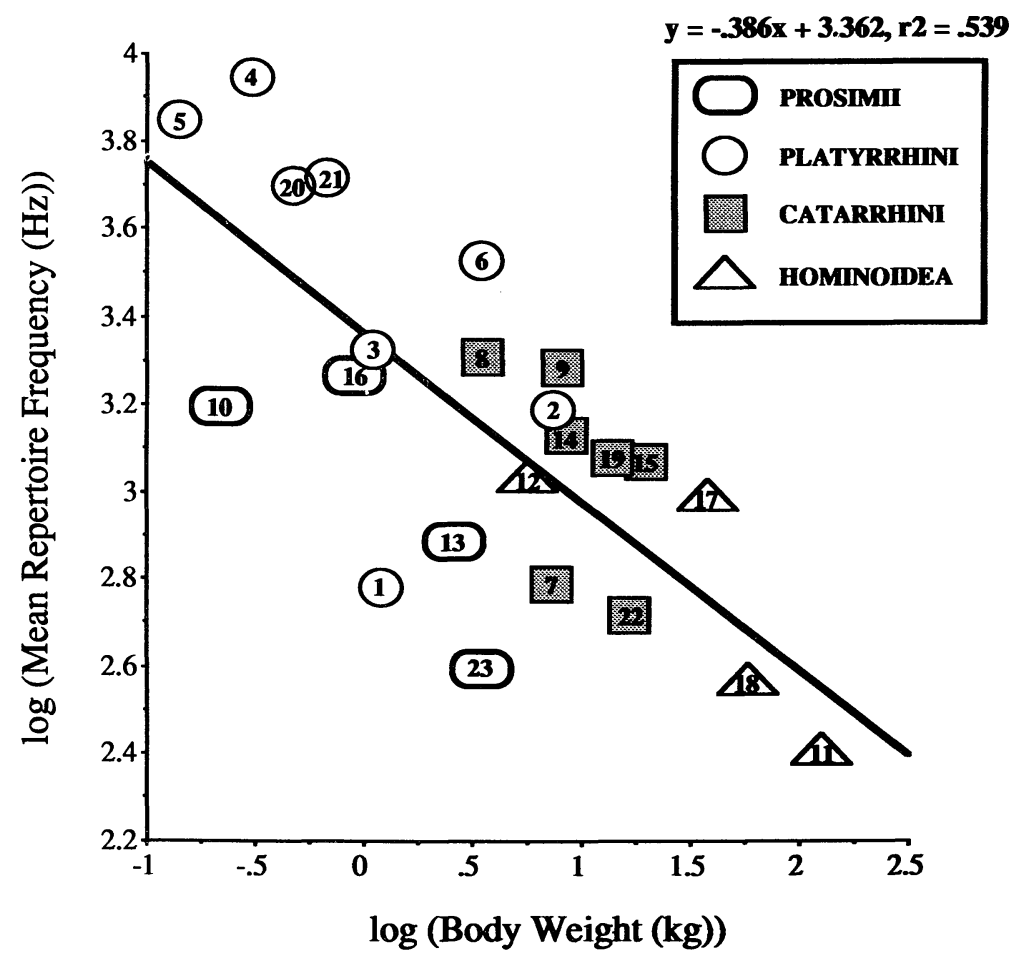

FIG. 1.-Regression of mean body weight $(\mathrm{kg})$ on mean repertoire frequency $(\mathrm{Hz})$; both axes $\log$ transformed. The numbers inside each symbol correspond to the following genera: 1, Aotus; 2, Ateles; 3, Callicebus; 4, Callithrix; 5, Cebuella; 6, Cebus; 7, Cercocebus; 8 , Cercopithecus; 9, Colobus; 10, Galago; 11, Gorilla; 12, Hylobates; 13, Lemur; 14, Macaca; 15, Mandrillus; 16, Nycticebus; 17, Pan; 18, Pongo; 19, Presbytis; 20, Saguinus; 21, Saimiri; 22, Theropithecus; 23, Varecia.

repertoires (Gautier 1988). When the data on body weight and frequency were plotted at the species level, there was a tendency for species within a genus to cluster around a common value. On the basis of this preliminary screening of the data and current thinking on phylogenetic analyses (Harvey and Pagel 1991), a generic level of analysis was used. Results revealed that there was a statistically significant relationship (fig. 1) between mean body weight and the mean frequency of calls in the repertoire $(R=0.73, F=24.56$, df $=1,22, P<.0001)$. In general, genera within each of the four major taxonomic groups (Prosimii, Platyrrhini, Catarrhini, Hominoidea) exhibited similar patterns. Thus, for a given body weight, all of the Prosimii tended to have slightly lower-frequency calls than expected, whereas most of the Platyrrhini had higher-frequency calls. Among the Catarrhini and Hominoidea, body weight accurately predicted call frequency. Some genera (e.g., Aotus, Callithrix, Cebus, Galago, and Varecia), however, showed quite extensive deviations from the predicted relationship between body weight and call frequency. For some of these genera, such deviations may be the 


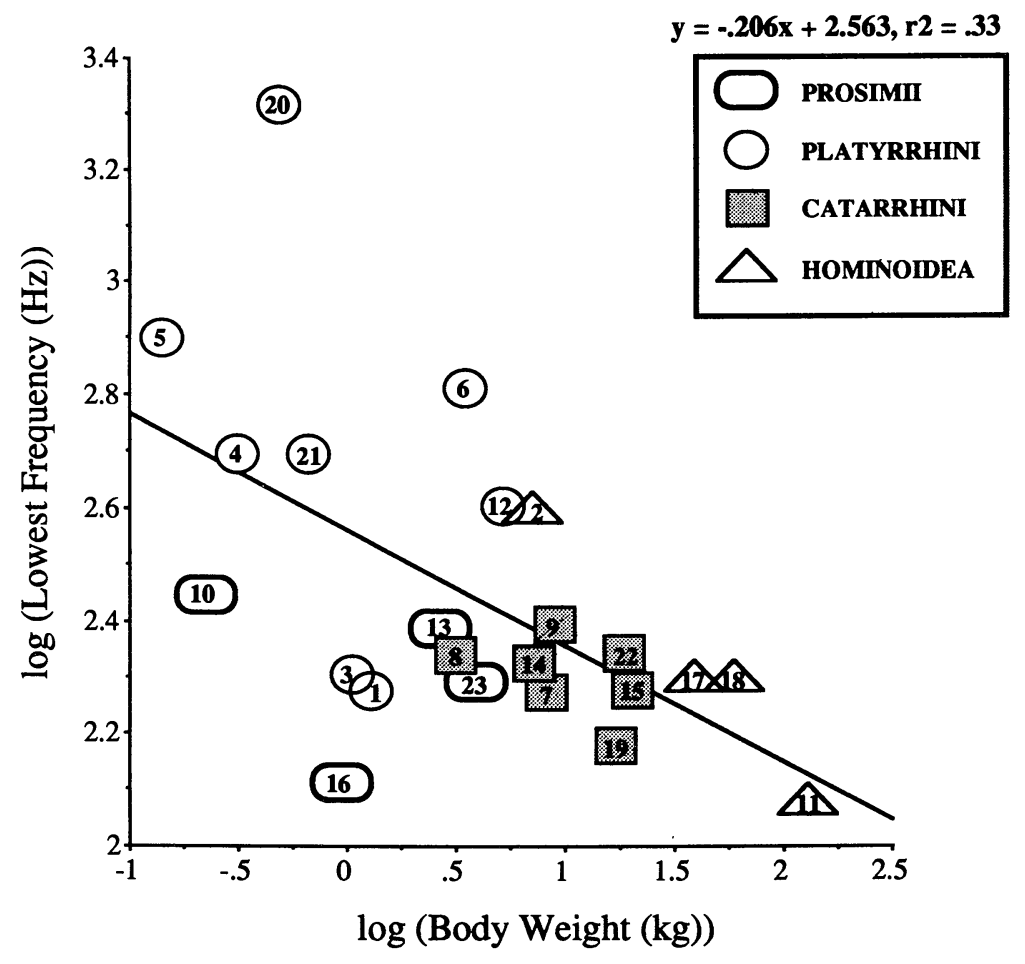

FIG. 2.- Regression of mean body weight $(\mathrm{kg})$ on the mean lowest frequency $(\mathrm{Hz})$ in the repertoire; both axes log transformed. See legend in fig. 1 for correspondence between numbers inside each symbol and genus.

result of sampling error (i.e., a small number of calls evaluated on the basis of spectrograms rather than quantitative spectral analyses).

Body weight constraints on call frequency could, theoretically, influence either the low or high end of a species' range. Consequently, the relationships between body weight and the lowest and highest frequencies in the repertoire were evaluated. There was a statistically significant relationship (fig. 2 ) between body weight and the lowest frequency in the repertoire $(R=0.57, F=10.14$, df $=1,21, P$ $<.0005)$, but the proportion of variation accounted for was relatively low $\left(R^{2}=\right.$ 0.33). When two extreme outliers (Nycticebus and Saguinus) were removed from the data set, the proportion of variation accounted for improved $\left(R^{2}=0.46\right)$. Thus, larger species produce relatively lower-pitched vocalizations than smaller species. There was also a statistically significant relationship (fig. 3) between body weight and the highest frequency in the repertoire $(R=0.72, F=22.64$, df $=1,21, P<.0001$ ), which thereby shows that larger species are more constrained than smaller species regarding the extent to which they can produce high-pitched vocalizations. Three genera, however, exhibited relatively pronounced deviations from the regression line: Aotus, Colobus, and Varecia. In contrast to the analyses of mean repertoire frequency, analyses of the lowest and 


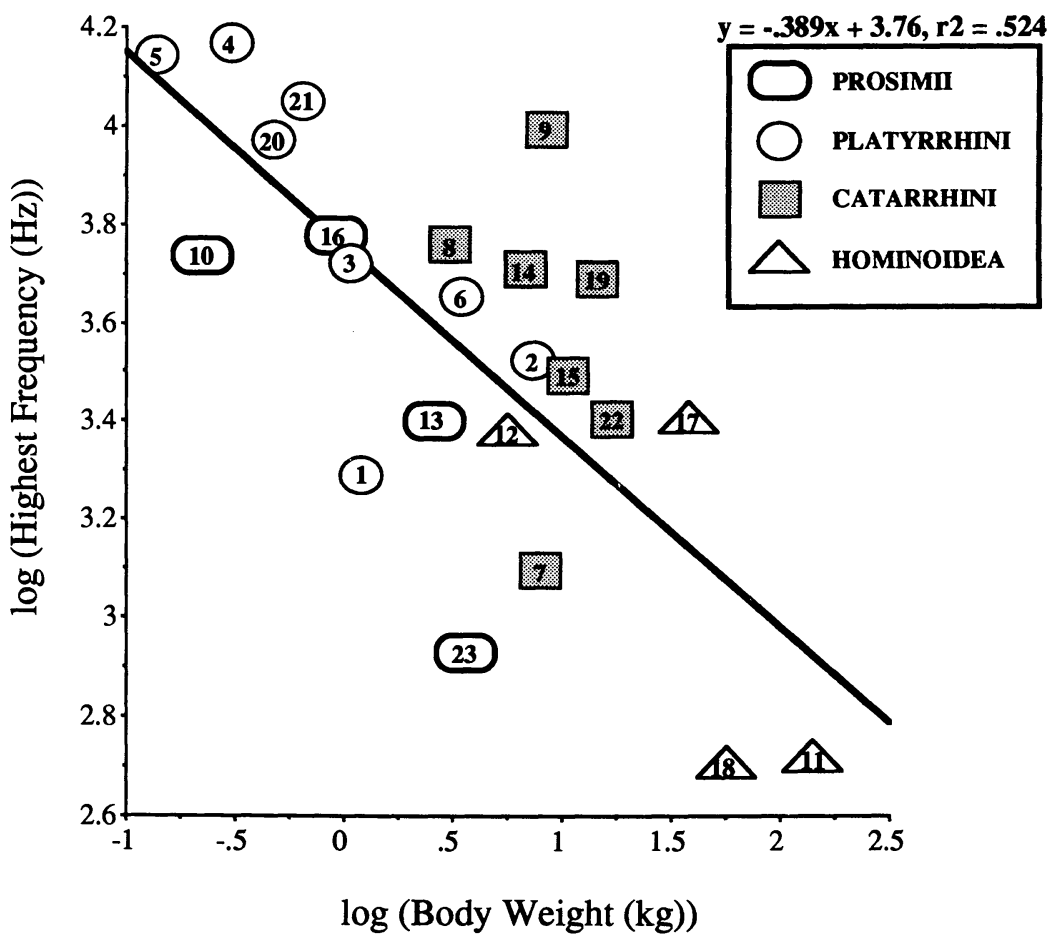

FIG. 3.-Regression of mean body weight $(\mathrm{kg})$ on the mean highest frequency $(\mathrm{Hz})$ in the repertoire; both axes log transformed. See legend in fig. 1 for correspondence between numbers inside each symbol and genus.

highest frequency did not reveal significant clustering of genera within higherorder taxonomic groupings (e.g., suborder or family).

The analyses presented thus far obscure within-genus variation. Macaca is the only genus for which a sufficient number of species have been evaluated to warrant a within-genus level of analysis. Figure 4 presents data on seven species of macaque, arranged according to body weight and the range of frequencies used in their vocal repertoires. These macaques differ by as much as $6.37 \mathrm{~kg}$ and by as much as $9,885 \mathrm{~Hz}$ at the high end of the frequency scale. However, such variation in the frequency domain does not appear to be related to body weight. For example, none of the calls produced by Macaca silenus exceed $475 \mathrm{~Hz}$, whereas Macaca radiata, which weighs only $0.49 \mathrm{~kg}$ less, produces calls as high as $10,360 \mathrm{~Hz}$. Interestingly, of all the macaque species evaluated, $M$. silenus is the only one consistently inhabiting a dense tropical rain forest environment; Macaca fascicularis is sometimes also found in comparable habitats. Because high-frequency components of a signal degrade more significantly than lowfrequency components in tropical habitats (Morton 1975; Marten et al. 1977; Brown and Waser 1988), ecological factors may be largely responsible for the observed differences between macaque species. 


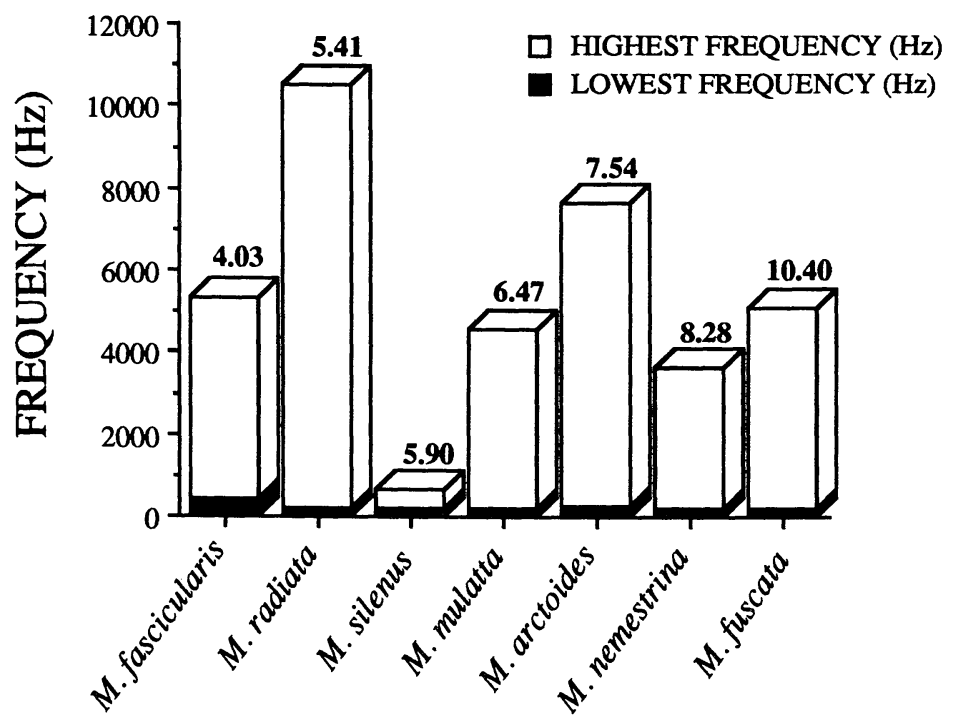

FIG. 4.-Relationship between call frequency $(\mathrm{Hz})$ and body weight $(\mathrm{kg})$ for seven species within the genus Macaca. The black portion of the histogram indicates the lowest frequency in the repertoire, and the white portion indicates the highest frequency. The numbers located above each histogram represent the species' weight $(\mathrm{kg})$. The order of species along the $X$-axis is from lowest to highest body weight.

Are Changes in Motivational State Reflected in the Acoustic Structure of Different Call Types?

There were 159 vocalizations for which a state of aggression or fear could be unambiguously assigned (table 1). Figure 5 shows the proportion of vocalizations within the repertoire of each species that were aggressive as opposed to fearful, as a function of frequency. As predicted by MS rules, 15 out of 23 species produced a greater proportion of high-frequency, fearful vocalizations than high-frequency, aggressive vocalizations (two-tailed sign test, $P=.026$ ). Similarly, 22 out of 33 species produced a greater proportion of low-frequency, aggressive vocalizations than low-frequency, fearful vocalizations (two-tailed sign test, $P=.036$ ). These results are, however, confounded by the fact that some taxonomic groups consistently support the MS rules prediction, whereas other groups do not. For example, in the high-frequency category, the Catarrhini provide 10 out of the 15 cases in which most of the calls in the repertoire are produced in the context of fear. Within the low-frequency class, nine out of 10 species of Platyrrhini produce a higher proportion of aggressive calls, whereas only nine out of 16 species of Catarrhini produce a higher proportion of aggressive calls. Interestingly, whereas six out of seven species of Macaca follow the predicted pattern for highfrequency calls, only two out of seven follow the predicted pattern for lowfrequency calls. This supports Morton's (1982) prediction that "some species might evolve to use only the aggressive end of the code while others use the entire 
HIGH FREQUENCY CALLS
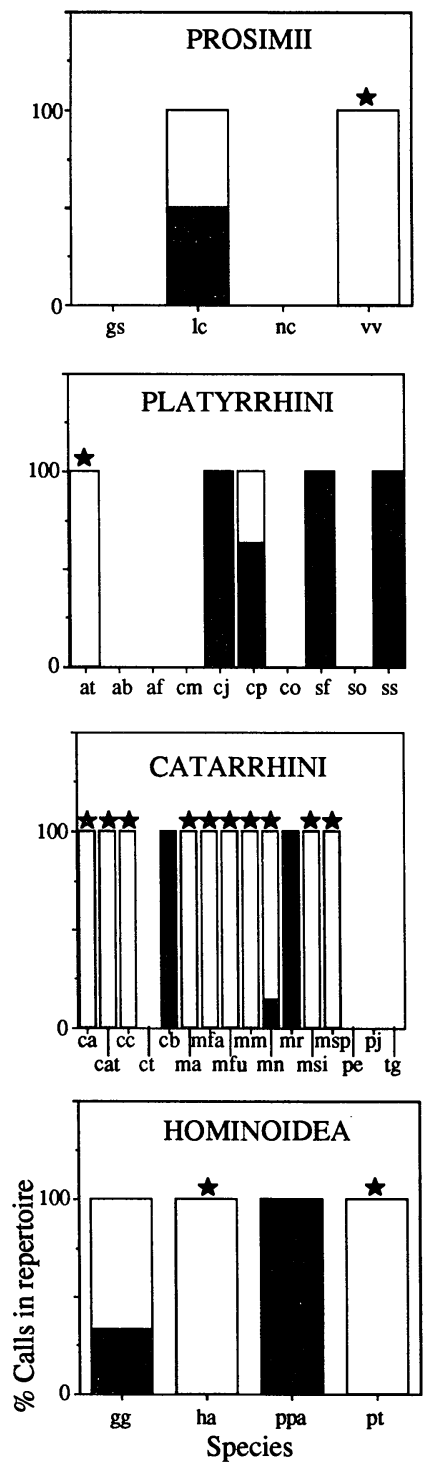

LOW FREQUENCY CALLS
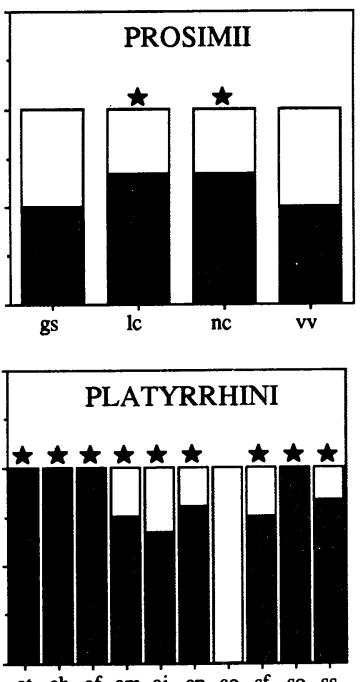

at ab af $\mathrm{cm} \mathrm{cj} \mathrm{cp} \mathrm{co} \mathrm{sf} \mathrm{so} \mathrm{ss}$
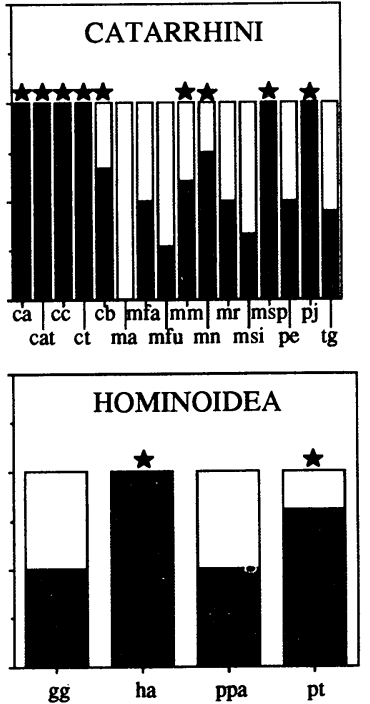

Fig. 5.-Relationship between motivational state and call frequency. The column on the left presents data on high-frequency calls, and the column on the right presents data on low-frequency calls. The black section of the histogram represents the proportion of calls in each species' repertoire that were classified as aggressive, and the white section indicates fearful calls. A star has been placed above each species where the prediction from MS rules is supported. Thus, stars have been placed above all species where a greater proportion of high-frequency calls are fearful and a greater proportion of low-frequency calls are aggressive. The $X$-axis represents species, coded as follows: gs, Galago senegalensis; lc, Lemur catta; nc, Nycticebus coucang; vv, Varecia variegata; at, Aotus trivirgatus; ab, Ateles 
code"' (p. 190). (Note that Morton modified his position on MS rules between his 1977 and 1982 publications. In particular, his revised framework allowed for greater flexibility in terms of the particular acoustic features selected by a given species to convey information about motivational state. Consequently, and as reflected in this quote, different species may use different aspects of the motivational structural code.)

In contrast to the significant association between motivational state and frequency, only eight out of 23 species produced a greater proportion of tonal calls in the context of fear (two-tailed sign test, $P=.953$ ) and only 12 out of 25 species produced more atonal calls in the context of aggression (two-tailed sign test, $P=$.655). Moreover, the failure to support the predicted relationship between tonality and motivational state was consistent for all taxonomic groups.

\section{DISCUSSION}

The comparative data presented in this report indicate that, among species of nonhuman primates, there is a statistically significant negative correlation between body weight and frequency. This relationship holds for the average, lowest, and highest frequency of calls in the repertoire. Thus, for the nonhuman primate species examined, body size imposes a significant constraint on call frequency. However, three caveats must be taken into account in evaluating this general result: within-genera variation, within-species variation, and a taxonomically restricted data set. Concerning the first, inspection of the genus Macaca revealed that body weight was a poor predictor of frequency range. The heaviest species within this genus (Macaca fuscata) did not produce calls with the lowest frequencies. On the contrary, there was little variation within this genus at the lowfrequency end, and one of the lightest macaque species (Macaca silenus) exhibited the narrowest range of calls (i.e., all below $500 \mathrm{~Hz}$ ). One factor that is most likely to account for such variation is habitat structure. Within the genus Macaca, most species live in open woodland environments. In contrast, $M$. silenus lives primarily in a tropical rain forest environment. Based on research in environmental acoustics (see, e.g., Marten et al. 1977; Brown and Waser 1988), it is clear that in areas with dense vegetation (e.g., tropical rain forests), animals tend to use relatively low-frequency signals since higher frequencies are more susceptible to degradation. Thus, $M$. silenus may exhibit a restricted frequency range not because of body size effects but because of habitat effects. If this hypothesis is correct, it suggests that analyses of acoustic structure should distinguish between an animal's potential to produce a particular type of signal and the type of signals produced (see Ryan 1988).

belzebuth; af, Ateles fusciceps; cm, Callicebus moloch; cj, Callithrix jacchus; cp, Cebuella pygmaea; cn, Cebus nigrivittatus; co, Cebus olivaceus; sf, Saguinus fuscicollis; so, Saguinus oedipus oedipus; ss, Saimiri sciureus; ca, Cercocebus albigena; cat, Cercopithecus aethiops; $c c$, Cercopithecus cephus; $c t$, Cercopithecus talapoin; cb, Colobus badius tephrosceles; ma, Macaca arctoides; mfa, Macaca fascicularis; $m f u$, Macaca fuscata; mm, Macaca mulatta; mn, Macaca nemestrina; $m r$, Macaca radiata; msi, Macaca silenus; msp, Mandrillus sphinx; pe, Presbytis entellus; pj, Presbytis johnii; tg, Theropithecus gelada; gg, Gorilla gorilla berengei; ha, Hylobates agilis; ppa, Pan paniscus; pt, Pan troglodytes. 
The second caveat raises the problem of within-species acoustic variation. A number of nonhuman primate species make use of an impressively wide range of frequencies. To take one example, rhesus monkeys (Macaca mulatta) produce a noisy pulsatile "grunt" with a fundamental frequency of $150 \mathrm{~Hz}$ and a tonal "food-associated call" with a fundamental frequency reaching 7,000 Hz (Hauser and Marler, in press $a$, in press $b$ ). Given the fact that rhesus monkeys weigh approximately $6.5 \mathrm{~kg}$, it is surprising that they produce some calls within the range of human adult males and other calls within the range of passerine birds. This ability to generate signals with a broad range of frequencies suggests that the laryngeal musculature of some nonhuman primates exerts a significant influence on vocal fold tension and consequently causes substantial changes in vocal fold vibration. Moreover, the frequency range observed implies that body weight may not necessarily be positively correlated with vocal fold mass. Comparative anatomical studies, such as those by Negus (1949) on nonhuman primates and by Ryan and Drewes (1990) on anurans would add significantly to our understanding of the problem.

The final caveat concerns the limitations of the comparative data set. Phylogenetic analyses represent a significant methodological challenge because one is often confronted with the task of establishing the appropriate level of analysis on the basis of fairly weak or incomplete evolutionary trees (Harvey and Pagel 1991). The nonhuman primate data fall into this methodological dilemma. A generic level of analysis was presented in this report because a preliminary inspection of the relationship between frequency and body weight revealed within-genus clustering. One problem with a generic level of analysis, however, is that some genera contain only one species whereas others, such as Macaca, contain several species. Unfortunately, the current data set is insufficient to explore the relationship between body weight and frequency on a higher taxonomic level of analysis or to use some of the more powerful statistical techniques (e.g., nested ANOVA) to examine the most appropriate level of analysis. As additional data on nonhuman primate vocal repertoires are collected and the evolutionary relationships between the primates are clarified, it will be possible to examine these issues in greater detail.

Results provide support for some of the predictions discussed by Morton (1977, 1982 ) in his work on motivational structural rules: vocalizations produced in the context of aggression tend to be low in frequency, whereas vocalizations produced in the context of fear tend to be high in frequency. However, there was no statistically significant relationship between motivational state and tonality.

There are at least two reasons why the nonhuman primate data failed to provide complete support for MS rules. First, it is possible that changes in motivational state are associated with other acoustic characteristics of the call that were not investigated in this report. For example, Goedeking (1988) examined the play vocalizations of cotton-top tamarins (Saguinus oedipus oedipus) and found that high-pitch instability (i.e., large changes in the fundamental frequency) was associated with a tendency to engage in playful wrestling. Similarly, I have observed (M. D. Hauser, unpublished data) that highly aroused rhesus monkeys (Macaca mulatta) waiting for access to food produce "coo" vocalizations that have a 
considerably greater amount of broad band noise than coos produced by individuals who are less aroused. Thus, future analyses of nonhuman primate vocalizations will need to consider the relationship between motivational state and a suite of acoustic parameters.

A second factor potentially influencing the outcome of my test of MS rules is that, for some nonhuman primates, the acoustic structure of the call is more closely related to the external referent (e.g., food, predator) than to the motivational state of the caller (reviewed in Cheney and Seyfarth 1990; Marler et al. 1992). For example, rhesus and pigtail macaques (Macaca nemestrina) produce five acoustically distinct scream vocalizations in the context of submissive interactions with dominant conspecifics (Gouzoules et al. 1984; Gouzoules and Gouzoules 1989); this class of vocalizations consists of tonal and atonal exemplars of both high and low pitch. Playback experiments using tape-recorded exemplars have shown that in rhesus monkeys each scream type provides information about the caller's relationship to the aggressor. Thus, the acoustic properties of the call are more closely associated with the external referent than with the motivational state of the caller, although the latter clearly plays an important role. Moreover, species may produce quite different calls in precisely the same context: in one context of submission, rhesus macaques produce an atonal scream, whereas pigtails produce a tonal scream.

In conclusion, the data presented suggest that the acoustic features of nonhuman primate vocalizations have been designed to convey information about motivational state and aspects of the external environment, including animate and inanimate stimuli. These features, in turn, have been constrained by vegetative and climatic properties of each species' typical environment. Given current advances in neurobiology, it will indeed be exciting to explore how neurophysiological and neuropsychological constraints on sound production and perception interact with a species' socioecology to shape the particular attributes of its communication system.

\section{ACKNOWLEDGMENTS}

For access to unpublished data and detailed comments on published data, I would like to thank D. Cheney, J. Eisenberg, A. Harcourt, H. Kudo, J. Macedonia, P. Marler, J. Robinson, R. Seyfarth, C. Snowdon, K. Stewart, and E. Zimmerman. Excellent comments on earlier versions of the manuscript were provided by J. Altmann, D. Cheney, T. Clutton-Brock, C. Evans, J. Macedonia, P. Marler, E. Morton, D. Nelson, D. Owings, M. Ryan, R. Seyfarth, and one anonymous reviewer for the American Naturalist. P. Harvey and B. Shaffer offered sound advice concerning phylogenetic treatment of the data. The author was supported by a National Institute of Health postdoctoral fellowship (PHS HD 07213-02) and a grant from the National Geographic Society (co-PI: P. Marler; \#4251-90).

LITERATURE CITED

Aich, H., R. Moos-Heilen, and E. Zimmerman. 1990. Vocalizations of adult gelada baboons (Theropithecus gelada): acoustic structure and behavioral context. Folia Primatologica 55:109-132. 
Andrew, R. J. 1963. The origin and evolution of the calls and facial expressions of the primates. Behaviour 20:1-109.

August, P. V., and J. G. T. Anderson. 1987. Mammal sounds and motivation-structural rules: a test of the hypothesis. Journal of Mammalogy 68:1-9.

Bertrand, M. 1969. The behavioral repertoire of the stumptail macaque. Bibliotheca Primatologica 11:1-273.

Brown, C., and P. Waser. 1988. Environmental influences on the structure of primate vocalizations. Pages 51-68 in D. Todt, P. Goedeking, and D. Symmes, eds. Primate vocal communication. Springer, Berlin.

Chalmers, N. R. 1968. The visual and vocal communication of free living mangabeys in Uganda. Folia Primatologica 9:258-280.

Cheney, D. L., and R. M. Seyfarth. 1988. Assessment of meaning and the detection of unreliable signals by vervet monkeys. Animal Behaviour 36:477-486.

1990. How monkeys see the world. University of Chicago Press, Chicago.

Cleveland, J., and C. T. Snowdon. 1982. The complex vocal repertoire of the adult cotton-top tamarin, Saguinus oedipus oedipus. Zeitschrift für Tierpsychologie 58:231-270.

Darwin, C. 1871. Expression of the emotions in man and animals. Appleton, London.

deWaal, F. B. M. 1988. The communicative repertoire of captive bonobos (Pan paniscus), compared to that of chimpanzees. Behaviour 106:183-251.

Eisenberg, J. F. 1976. Communication mechanisms and social integration in the black spider monkey, Ateles fusciceps robustus, and related species. Smithsonian Contributions in Zoology 213:1-108.

Epple, G. 1968. Comparative studies on vocalizations in marmoset monkeys. Folia Primatologica 8:1-40.

Gautier, J.-P. 1974. Field and laboratory studies of the vocalizations of talapoin monkeys (Miopithecus talapoin). Behaviour 51:209-273.

1978. Repertoire sonore de Cercopithecus cephus. Zeitschrift für Tierpsychologie 46:113-169. 1988. Interspecific affinities as deduced from vocalizations among African guenons. Pages 194-226 in A. Gautier-Hion, F. Bourliere, J.-P. Gautier, and J. Kingdon, eds. A primate radiation: evolutionary biology of the African guenons. Cambridge University Press, Cambridge.

Goedeking, P. 1988. Vocal play behavior in cotton-top tamarins. Pages 133-144 in D. Todt, P. Goedeking, and D. Symmes, eds. Primate vocal communication. Springer, Berlin.

Gouzoules, H., and S. Gouzoules. 1989. Design features and developmental modification in pigtail macaque (Macaca nemestrina) agonistic screams. Animal Behaviour 37:383-401. 1990. Body size effects on the acoustic structure of pigtail macaque (Macaca nemestrina) screams. Ethology 85:324-334.

Gouzoules, S., H. Gouzoules, and P. Marler. 1984. Rhesus monkey (Macaca mulatta) screams: representational signalling in the recruitment of agonistic aid. Animal Behaviour 32:182-193.

Green, S. 1975. Variation of vocal pattern with social situation in the Japanese monkey (Macaca fuscata): a field study. Pages 1-102 in L. A. Rosenblum, ed. Primate behavior. Vol. 4. Academic Press, New York.

Grimm, R. J. 1967. Catalogue of sounds of the pigtailed macaque (Macaca nemestrina). Journal of Zoology (London) 152:361-373.

Harvey, P. H., and M. D. Pagel. 1991. The comparative method in evolutionary biology. Oxford University Press, Oxford.

Harvey, P. H., R. D. Martin, and T. H. Clutton-Brock. 1987. Life histories in comparative perspective. Pages 181-196 in B. B. Smuts, D. L. Cheney, R. M. Seyfarth, R. W. Wrangham, and T. T. Struhsaker, eds. Primate societies. University of Chicago Press, Chicago.

Hauser, M. D. 1989. Ontogenetic changes in the comprehension and production of vervet monkey (Cercopithecus aethiops) vocalizations. Journal of Comparative Psychology 103:149-158. 1991. Sources of acoustic variation in rhesus macaque vocalizations. Ethology 89:29-46. 1992. Articulatory and social factors influence the acoustic structure of rhesus monkey vocalizations: a learned mode of production? Journal of the Acoustical Society of America 91:2175-2179. 
Hauser, M. D., and C. A. Fowler. 1991. Declination in fundamental frequency is not unique to human speech: evidence from nonhuman primates. Journal of the Acoustical Society of America 91:363-369.

Hauser, M. D., and P. Marler. In press $a$. Food-associated calls in rhesus macaques (Macaca mulatta). I. Socioecological factors influencing call production. Behavioral Ecology.

- In press $b$. Food-associated calls in rhesus macaques (Macaca mulatta). II. Costs and benefits of call production and suppression. Behavioral Ecology.

Hauser, M. D., C. S. Evans, and P. Marler. 1993. The role of articulation in the production of rhesus monkey (Macaca mulatta) vocalizations. Animal Behaviour 45:423-433.

Hohmann, G. 1989a. Vocal communication of wild bonnet macaques (Macaca radiata). Primates 30:325-345.

- 1989b. Comparative study of vocal communication in two Asian leaf monkeys, Presbytis johnii and Presbytis entellus. Folia Primatologica 52:27-57.

Hohmann, G., and Herzog, M. O. 1985. Vocal communication in lion-tailed macaques. Folia Primatologica 45:148-178.

Jürgens, U. 1979. Vocalizations as an emotional indicator: a neuroethological study in the squirrel monkey. Behaviour 69:88-117.

Kudo, H. 1987. The study of vocal communication of wild mandrills in Cameroon in relation to their social structure. Primates 28:289-308.

Macedonia, J. M. 1986. Individuality in the contact call of the ring-tailed lemur (Lemur catta). American Journal of Primatology 11:163-179.

- 1990. Vocal communication and antipredator behavior in ring-tailed lemurs (Lemur catta). Ph.D. diss. Duke University, Durham, N.C.

1991. What is communicated in the antipredator calls of lemurs: evidence from playback experiments with ring-tailed and ruffed lemurs. Ethology 86:177-190.

In press. The vocal repertoire of the ring-tailed lemur (Lemur catta). Behaviour.

Mackinnon, J. 1974. The behaviour and ecology of wild orang-utans (Pongo pygmaeus). Animal Behaviour 22:3-74.

Marler, P., and R. Tenaza. 1977. Communication in apes with special reference to vocalizations. Pages 965-1033 in T. A. Sebeok, ed. How animals communicate. Indiana University Press, Bloomington.

Marler, P., C. S. Evans, and M. D. Hauser. 1992. Animal vocal signals: reference, motivation, or both? Pages 66-86 in H. Papousek, U. Jürgens and M. Papousek, eds. Nonverbal vocal communication. Cambridge University Press, Cambridge.

Marten, K., D. B. Quine, and P. Marler. 1977. Sound transmission and its significance for animal vocalization. II. Tropical habitats. Behavioral Ecology and Sociobiology 2:291-302.

McCoomb, K. E. 1991. Female choice for high roaring rates in red deer, Cervus elaphus. Animal Behaviour 41:79-88.

Moody, D. B., W. C. Stebbins, and B. J. May. 1990. Auditory perception of communication signals by Japanese monkeys. Pages 311-344 in W. C. Stebbins and M. A. Berkley, eds. Comparative perception: complex perception. Wiley, New York.

Moody, M. I., and E. W. Menzel, Jr. 1976. Vocalizations and their behavioral contexts in the tamarin Saguinus fuscicolis. Folia Primatologica 25:73-94.

Morton, E. S. 1975. Ecological sources of selection on avian sounds. American Naturalist 109:17-34.

1977. On the occurrence and significance of motivation-structural rules in some birds and mammal sounds. American Naturalist 111:855-869.

1982. Grading, discreteness, redundancy, and motivation-structural rules. Pages 183-212 in D. Kroodsma and E. Miller, eds. Acoustic communication in birds. Vol. 1. Academic Press, New York.

Moynihan, M. 1964. Some behaviour patterns of platyrrhine monkeys. I. The night monkey (Aotus trivirgatus). Smithsonian Miscellaneous Collections 146(5):1-84.

- 1966. Communication in the titi monkey Callicebus. Journal of Zoology (London) 150:77-127.

Negus, V. 1949. The comparative anatomy and physiology of the larynx. Hafner, New York.

Newman, J. 1985. Squirrel monkey communication. Pages 99-125 in L. A. Rosenblum and C. L. Coe, eds. Handbook of squirrel monkey research. Plenum, New York. 
Owren, M. J., and R. Bernacki. 1988. The acoustic features of vervet monkey (Cercopithecus aethiops) alarm calls. Journal of the Acoustical Society of America 83:1927-1935.

Palombit, R. 1992. A preliminary study of vocal communication in wild long-tailed macaques (Macaca fascicularis). I. Vocal repertoire and call emission. International Journal of Primatology 13:143-182.

Pola, Y., and C. T. Snowdon. 1975. The vocalizations of pygmy marmosets (Cebuella pygmaea). Animal Behaviour 23:826-842.

Robinson, J. G. 1979. An analysis of the organization of vocal communication in the titi monkey Callicebus moloch. Zeitschrift für Tierpsychologie 49:381-405.

1982. Vocal systems regulating within-group spacing. Pages 94-116 in C. T. Snowdon, C. R. Brown, and M. R. Petersen, eds. Primate communication. Cambridge University Press, Cambridge.

1984. Syntactic structures in the vocalizations of wedge-capped capuchin monkeys Cebus nigrivittatus. Behaviour 90:46-79.

Ryan, M. J. 1988. Constraints and patterns in the evolution of anuran acoustic communication. Pages 637-677 in B. Fritzsch, M. J. Ryan, W. Wilczynski, T. E. Hetherington, and W. Walkowiak, eds. The evolution of the amphibian auditory system. Wiley, New York.

Ryan, M. J., and R. C. Drewes. 1990. Vocal morphology of the Physalaemus pustulosus species group (Leptodactylidae): morphological response to sexual selection for complex calls. Biological Journal of the Linnaean Society 40:37-52.

Seyfarth, R. M., and D. L. Cheney. 1984. The acoustic features of vervet monkey grunts. Journal of the Acoustical Society of America 75:129-134.

1990. The assessment by vervet monkeys of their own and another species' alarm calls. Animal Behaviour 40:754-764.

Seyfarth, R. M., D. L. Cheney, and P. Marler. 1980. Vervet monkey alarm calls: semantic communication in a free-ranging primate. Animal Behaviour 28:1070-1094.

Struhsaker, T. T. 1967. Auditory communication among vervet monkeys (Cercopithecus aethiops). Pages 281-324 in S. A. Altmann, ed. Social communication among primates. University of Chicago Press, Chicago.

1970. The red colobus monkey. University of Chicago Press, Chicago.

Zimmerman, E. 1985a. The vocal repertoire of the adult Senegal bushbaby (Galago senegalensis senegalensis). Behaviour 94:212-233.

1985b. Vocalizations and associated behaviours in adult slow loris (Nycticebus coucang). Folia Primatologica 44:52-64. 